\title{
Efficacy of transverse cerebellar diameter/abdominal circumference ratio: a gestational age independent parameter in assessing fetal growth restriction
}

\author{
Saritha Chinnappan*, Malarvizhi Loganathan
}

Department of Obstetrics and Gynecology, Government Dharmapuri Medical College Hospital, Dharmapuri, Tamil Nadu, India

Received: 18 November 2017

Accepted: 18 December 2017

*Correspondence:

Dr. Saritha Chinnappan,

E-mail: drsarimkumaran@gmail.com

Copyright: (c) the author(s), publisher and licensee Medip Academy. This is an open-access article distributed under the terms of the Creative Commons Attribution Non-Commercial License, which permits unrestricted non-commercial use, distribution, and reproduction in any medium, provided the original work is properly cited.

\section{ABSTRACT}

Background: It is important to identify fetal growth restriction (FGR) antenatally because it is associated with increased perinatal morbidity and mortality. There is difficulty in diagnosis of fetal growth restriction using standard ultrasonographic parameters as they are gestational age related and are not reliable in cases of symmetrical growth restriction. Therefore, there is a need for gestational age independent biometric parameter, which can diagnose fetal growth restriction in unknown gestational age and can diagnose both symmetric and asymmetric fetal growth restriction. In this study transverse cerebellar diameter (TCD)/abdominal circumference (AC) ratio used to diagnose fetal growth restriction. Objectives of the study were to evaluate the validity of TCD/AC ratio in diagnosing fetal growth restriction and to find out the cut-off value of TCD/AC ratio for diagnosis of fetal growth restriction.

Methods: This study was carried out for 12 months and sample size was 100. Transverse cerebellar diameter, abdominal circumference measured between 20-22wks and 32-34weeks of gestation and transverse cerebellar diameter and abdominal circumference ratio calculated.

Results: TCD/AC ratio was fairly constant throughout the pregnancy. Fetuses with TCD/AC ratio more than 2SD of the mean were found growth restricted on examination. The TCD/AC ratio more accurate in diagnosing fetal growth restriction (FGR).

Conclusions: As the TCD/AC ratio is constant, it is a gestational age - independent parameter, can diagnose FGR in antenatal women with unknown gestational age. Hence, TCD/AC ratio can be a screening test to diagnose FGR in the antenatal period.

Keywords: AC, FGR, Gestational age, Perinatal morbidity, TCD, TCD/AC ratio

\section{INTRODUCTION}

The Process of birth is the most dangerous journey an individual undertakes. A healthy new born is the goal of every expectant mother and her obstetrician.

It is estimated that the incidence of fetal growth restriction is $3-10 \% .^{1}$. Fetal growth restriction is associated with substantial perinatal morbidity and mortality. Fetal demise, birth asphyxia, meconium aspiration, neonatal hypoglycemia and hypothermia are all increased in growth restriction. In addition, it has been also found that these growth restricted infants have increased 1year infant mortality rate and abnormal neurological development.

The assessment of fetal growth is important to the provision of optimum prenatal care. As the clinical 
estimation of the fetal growth is not reliable, prenatal ultrasonography provides an opportunity to more accurately assess the fetal growth. The most commonly used parameters to evaluate fetal growth are biparietal diameter (BPD), head circumference (HC), abdominal circumference (AC) and femur length (FL). Of all the ultrasound derived biometric parameters, the AC seems to be the best predictor of fetal growth restriction (FGR). But all these parameters can be correlated only if gestational age is accurately known. But uncertainty of the gestational age occurs frequently and makes the differentiation between the appropriate for gestational age and the small for gestational age fetus difficult.

Measurement of transverse cerebellar diameter (TCD) is an accurate method of estimating gestational age in cases of uncertain dates and even in dolicocephaly or brachycephaly where biparietal diameter could not be used. It has been proposed that TCD is not affected in fetal growth restriction because of the brain sparing effect. $^{2}$ Fetal AC is affected early in the process of growth restriction. ${ }^{3}$ Hence, TCD/AC ratio increases in fetal growth restriction which fairly remains constant throughout normal pregnancy. ${ }^{4}$ TCD/AC ratio may convey more precise information regarding the fetal growth and development than bony measurements of the fetal head and AC alone. This study was primarily planned to study the TCD among pregnant women and to find whether TCD/AC ratio can diagnose fetal growth restriction.

Objectives of the study were to evaluate the validity of TCD/AC ratio in diagnosing fetal growth restriction and to find out the cut-off value of $\mathrm{TCD} / \mathrm{AC}$ ratio for diagnosis of fetal growth restriction.

\section{METHODS}

A prospective study consisting of 100 antenatal women was conducted in Government RSRM Lying in Hospital, Stanley medical college, Chennai during the period from November 2010 to October 2011.

\section{Inclusion criteria}

- Antenatal women with singleton live intrauterine gestation

- Antenatal women with excellent dates.

\section{Exclusion criteria}

- Antenatal women with unreliable dates

- Antenatal women with fetal anomalies

- Antenatal women with multiple gestations

Antenatal women were enrolled after written informed consent. A detailed history of the patients was taken. A thorough systemic and obstetric examination was made. All preliminary investigations were done. The antenatal women were made aware of the benefits of ultrasonogram. These women were offered ultrasonogram between 20-22 weeks of gestation. The scans were carried out by the trained sonologist. With ultrasonogram the transverse cerebellar diameter (TCD) and abdominal circumference $(\mathrm{AC})$ of fetus were measured in addition to anomaly scanning, routine biometric parameters and liquor volume. The TCD/AC ratio was calculated. These women were informed about the results of the scan. These women were informed to come between 32-34 weeks for repeat scan. The patients were followed up till delivery.

All babies at birth were assessed by the neonatologist and grouped as appropriate for gestational age (AGA) or fetal growth restriction (FGR) according to birth weight 10th 90th percentile and <10th percentile for gestational age respectively.

The babies were typed as symmetric or asymmetric IUGR based on ponderal index. Apgar score, NICU admission in days and perinatal outcome were noted. The cut-off of value of TCD/AC ratio for diagnosing FGR arrived by finding mean+2SD of TCD/AC ratio of AGA fetuses.

\section{Statistical analysis}

Statistical analysis was performed with SPSS software (version 15.00 for windows). To find out the statistical significance, linear regression, one way ANOVA (analysis of variance) test and student ' $t$ ' test was done. For the purpose of this study $95 \%$ confidence interval has been chosen and ' $p$ ' value $<0.05$ has been taken as significant.

The TCD/AC ratio >2SD considered to be at risk of having fetal growth restriction. Women who had TCD/AC > 2SD at 20-22 weeks are considered to be at risk of symmetric FGR and at 32-34 weeks for asymmetric FGR.

\section{RESULTS}

Antenatal women in the study group were in 18-34 years with majority of the study population in the age group of $21-25$ years. $63 \%$ of the patients in the study were primigravida and $37 \%$ were multigravida. Risk factors associated with present pregnancy were pre-eclampsia in $9 \%$, chronic hypertension in $1 \%$, oligohydramnios in $5 \%$ and GDM in $2 \%$.

In 100 antenatal women, 10 were delivered FGR babies. In our study $94 \%$ of patients were delivered at term and $6 \%$ of patients were delivered preterm. Out of 6 cases of preterm $33.3 \%$ were delivered FGR babies with TCD within mean $+2 \mathrm{SD}$ of normal pregnancies.

Strong correlation existed between gestational age and TCD (Table 1), gestational age and AC and between TCD and AC in pregnancies with AGA fetuses. 
Table 1: Correlation of gestational age with TCD.

\begin{tabular}{|lll|}
\hline Gestational age & Correlation coefficient & P value \\
\hline 20-22 weeks & $\mathrm{R}=0.862$ & $<0.001$ \\
\hline $32-34$ weeks & $\mathrm{R}=0.803$ & $<0.001$ \\
\hline
\end{tabular}

There was no statistically significant difference between the mean TCD of FGR and AGA fetuses whereas there was statistically significant difference between the mean AC of FGR and AGA foetuses (Table 2). In pregnancies with FGR strong correlation existed between gestational age and TCD.

Table 2: Correlation of TCD and AC with in utero growth status at 32-34 weeks.

\begin{tabular}{|c|c|c|c|c|c|}
\hline \multirow{3}{*}{$\begin{array}{l}\text { Study } \\
\text { parameters }\end{array}$} & \multicolumn{4}{|c|}{ In utero growth status } & \multirow{3}{*}{$\begin{array}{l}\mathbf{P} \\
\text { value }\end{array}$} \\
\hline & \multicolumn{2}{|l|}{ FGR } & \multicolumn{2}{|l|}{ AGA } & \\
\hline & Mean & SD & Mean & SD & \\
\hline TCD & 3.96 & 0.18 & 4.03 & 0.15 & 0.183 \\
\hline $\mathrm{AC}$ & 24.1 & 1.18 & 27.87 & 1.48 & $<0.001$ \\
\hline
\end{tabular}

Table 3: Comparison of TCD/AC ratio at 20- 22 weeks and 32-34 weeks in AGA fetuses.

\begin{tabular}{|lll|}
\hline GA & TCD/AC ratio & P value \\
\hline 20-22 weeks & $14.29 \pm 0.73(\mathrm{SD})$ & $>0.073$ \\
\hline $32-34$ weeks & $14.49 \pm 0.62(\mathrm{SD})$ & \\
\hline
\end{tabular}

There was no statistically significant difference between the TCD/AC ratio at 20-22 weeks and 32-34weeks in AGA foetuses (Table 3).

Correlation were not significant between gestational age and AC, and TCD and AC in FGR fetuses. The cut-off value of TCD/AC ratio for diagnosing FGR was arrived from mean+2SD of AGA fetuses at 32-34 weeks. The mean TCD/AC ratio for AGA fetuses in this study was $14.49 \pm 0.62$ (SD). The cut-off value in our study was 15.73 (mean+2SD). This cut-off value of TCD/AC ratio diagnosed 8 out of 10 cases of FGR (Table 4).

Table 4: Distribution of FGR/AGA fetuses with respect to cut-off value of TCD/AC ratio at 32-34 weeks.

\begin{tabular}{|llll|}
\hline TCD/ AC Ratio & FGR & AGA & Total \\
$\mathbf{1 4 . 4 9 + 2 S D}(\mathbf{1 . 2 4})$ & & 89 & 91 \\
\hline$\leq 15.73$ & 2 & 1 & 9 \\
\hline$>15.73$ & 8 & 90 & 100 \\
\hline Total & 10 & & \\
\hline
\end{tabular}

Table 5: Mean TCD/AC ratio in FGR and AGA fetuses at 32-34 weeks.

\begin{tabular}{|llll|}
\hline $\begin{array}{l}\text { In utero } \\
\text { growth status }\end{array}$ & $\begin{array}{l}\text { TCD/AC } \\
\text { Ratio }\end{array}$ & $\begin{array}{l}\text { No. of } \\
\text { babies }\end{array}$ & P value \\
\hline FGR & 16.44 & 10 & $<0.001$ \\
\hline AGA & 14.49 & 90 & $<0$ \\
\hline
\end{tabular}

There was statistically significant difference between the mean TCD/AC ratio of FGR and AGA foetuses (Table 5).

\section{DISCUSSION}

In this study out of 100 pregnant women $10 \%$ were delivered FGR babies (birth weight <10th percentile), which is similar to general incidence of $3-10 \% .{ }^{1}$ A strong correlation was noted between gestational age determined by last menstrual period and fetal TCD between 20-22 weeks $(r=0.0 .862)$ and 32-34 weeks $(r=0.803)$ $(\mathrm{p}<0.001)$, similar to correlation of TCD and gestational age $(r=0.955)$ in the study conducted by Haller et al. ${ }^{5}$

In the study conducted by Dilmen et al the pearson correlation $\mathrm{r}=0.9767$, which is also close to present study. ${ }^{6}$ In present study a significant correlation exists between the gestational age determined by the last menstrual period and AC at 20-22 weeks $(r=0.688)$ and 32-34 weeks $(r=0.486) \quad(\mathrm{p}<0.001)$. In the study conducted by Haller et al there was strong correlation exists between gestational age and AC $(r=0.9453)$ which is almost close to present study. ${ }^{5}$ There was a significant linear correlation noted between TCD and AC at 20-22 weeks $(r=0.790)$ and $32-34$ weeks $(r=0.588)(P<0.01)$ in this study, similar to study conducted by Campbell et al where strong linear correlation $(r=0.918)$ noted between TCD and AC. ${ }^{7}$

In present study there is no statistically significant difference between the mean TCD of FGR and AGA fetuses $(p>0.05)$, Similar to study conducted by Reece et al, in which the TCD was not affected in FGR. ${ }^{8}$ In another study conducted by Vinkesteijn et al, the TCD was only mildly affected even in severe FGR, this is also close to present study. ${ }^{9}$ The concept that TCD is not affected in FGR, is explained by the sparing of blood flow to the cerebellum in IUGR as suggested by Berhman et al. ${ }^{2}$

This study shows a statistically significant difference between the mean AC of FGR and AGA fetuses $(p<0.001)$. This again proves that in FGR the AC will be affected more as the liver size is reduced due to reduced glycogen store. In present study the TCD/AC ratio was 14.29 \pm 73 (SD) at 20-22 weeks (TCD/AC ratio) and $14.49 \pm 0.62$ at $32-34$ weeks (TCD/AC ratio) for normal pregnancies. There was no statistical difference between the two values implying that TCD/AC ratio was fairly constant throughout pregnancy, similar to study conducted by Meyer et al, in which the TCD/AC ratio remained constant throughout pregnancy with respect to gestational age. ${ }^{10}$

In another study conducted by Campbell et al, the ratio calculated after each examination and the ratio remained constant which is also similar to present study. ${ }^{7}$ In this study the mean $+2 \mathrm{SD}$ of the TCD/AC ratio at $32-34$ weeks is taken as cut-off value for diagnosing FGR. The 
cut-off value of TCD/AC ratio 15.73 in present study is close to the study conducted by Meyer et al in which the cut-off value for fetal growth restriction was 15.9, and also with the study of Haller et al. ${ }^{5,10}$ In present study the sensitivity, specificity, PPV and NPV of TCD/AC ratio in diagnosing FGR were $80 \%, 98.8 \%, 88.8 \%$ and $97.8 \%$ respectively. Which is comparable with the study of Meyer et al in which the sensitivity, specificity, PPV and NPV were $83.9 \%, 96.8 \%, 94.5 \%$ and $88.2 \%$ respectively. ${ }^{10}$ In present study out of 10 cases of FGR 9 were asymmetrical and one symmetrical. Out of 9 cases of asymmetric FGR 7 were diagnosed by the cut-off value of TCD/AC ratio with the sensitivity of $77.7 \%$, similar to study of Meyer et al where the sensitivity is $83.9 \% .{ }^{10}$ In present study one was symmetrical FGR which was diagnosed by the TCD/AC ratio with the sensitivity of $100 \%$. In the study conducted by Meyer et al, TCD/AC ratio diagnosed symmetric FGR with a sensitivity of $71 \% .^{10}$

In present study the higher sensitivity is probably because of small sample size. In present study one was found to be severe FGR which had TCD/AC ratio within cut-off value, and this is due to the fact that cerebellum mildly affected in severe FGR, similar to study by Vinkesteijn et al.9 In present study, significant negative correlation exists between the TCD/AC ratio and the birth weight. Perinatal morbidity was high in FGR babies compared to AGA babies. Perinatal mortality was $20 \%$ in FGR babies.

\section{CONCLUSION}

The TCD and AC measurements correlates well with gestational age. The TCD and AC has strong linear relationship, hence the TCD/AC ratio is fairly constant throughout pregnancy. TCD unlike AC is not affected in FGR, because of brain sparing. Hence, TCD/AC ratio is increased in FGR.

As the TCD/AC ratio is constant throughout the pregnancy, it is a gestational age independent parameter, can diagnose FGR in antenatal women with unknown gestational age. Hence, TCD/AC ratio can be a screening test to diagnose FGR in the antenatal period. So, that early intervention could be attempted to improve the perinatal outcome.

Funding: No funding sources Conflict of interest: None declared

Ethical approval: The study was approved by the Institutional Ethics Committee

\section{REFERENCES}

1. Williams. Fetal growth disorders. Obstetrics. $23^{\text {rd }}$ ed. McGraw-Hill Companies;2010:843.

2. Berhman RE, Hers MH, de Peterson EN, Lannoy $\mathrm{CW}$, Seeds AE. Distribution of the circulation in the normal and asphyxiated primate. Am J Obstet Gynecol. 1970;108:956-96.

3. Hadlock FP, Deter RL, Harrist RB. Sonographic detection of abnormal growth patterns. Clin Obstet Gynecol. 1984;27:342-51.

4. Meyer WJ, Gauthier DW, Goldenberg B, Santolaya J, Sipos J, Catledge F. The fetal transverse cerebellar diameter/abdominal circumference ratio: a gestational age- independent method of assessing fetal size. J Ultrasoud Med. 1993 Jul;12(7):379-82.

5. Haller H, Petrović O, Rukavina B. Fetal transverse cerebellar diameter/abdominal circumference ratio in assessing fetal size. Int J Gynecol Obstet. 1995 Aug 1;50(2):159-63.

6. Dilmen G, Toppare MF, Turhan NÖ, Öztürk M, Işik S. Transverse cerebellar diameter and transverse cerebellar diameter/abdominal circumference index for assessing fetal growth. Fetal Diagn Ther 1996;11:50-6.

7. Campbell WA, Nardi D, Vintzileos AM, Rodis JF, Turner GW, Egan JF. Transverse cerebellar diameter/abdominal circumference ratio throughout pregnancy: a gestational age-independent method to assess fetal growth. Obstet Gynecol. 1991 Jun;77(6):893-6.

8. Goldstien I, Reece EA, Gianluigi P, Bovicelli L, Hobbins JC. Cerebellar measurements with ultrasonography in the evaluation of fetal growth and development. Am J Obstet Gynecol. 1987;156:10659.

9. Vinkesteijn AS, Mulder PG, Wlamidiroff JW. Fetal transverse cerebellar diameter measurements in normal and reduced fetal growth. Ultrasound Obstet Gynecol. 2000;15:47-51.

10. Meyer WJ, Gauthier D, Ramakrishnan V, Sipos J. Ultrasonographic detection of abnormal fetal growth with the gestational age-independent, transverse cerebellar diameter /abdominal circumference ratio. Am J Obstet Gynecol. 1994;171:1057.

Cite this article as: Chinnappan S, Loganathan $\mathrm{M}$. Efficacy of transverse cerebellar diameter/abdominal circumference ratio: a gestational age independent parameter in assessing fetal growth restriction. Int J Reprod Contracept Obstet Gynecol 2018;7:142-5. 